\title{
Fabrication of Tissue Engineering Scaffold from Hydroxyapatite/Alginate Composite
}

\author{
Masoumeh Haghbin Nazarpak and Farzaneh Pourasgari
}

\begin{abstract}
Scaffolds for bone tissue engineering must meet the functional requirements, porosity, biocompatibility, and biodegradability. In this study, hydroxyapatite was prepared by wet chemical method and incorporated into the alginate gel solution to improve both the mechanical and cell-attachment properties of the scaffolds. Next, composite scaffolds were fabricated from hydroxyapatite/alginate with different weight ratios by freeze drying method and then some of them coated with triblock copolymer and compared with others. Microstructure observation with SEM suggests the formation of about 50 micrometer size porous structure and interconnected porosity. Then, human mesenchymal stem cells were cultured on the composite scaffolds. Cells adhesion to the scaffolds was observed after three days by DAPI fluorescence microscopy in which more cells adhesion to the coated scaffolds and cells diffusion into the pores are visible. Also, cell adhesion within the structure was observed by SEM in which showed cell attachment was well in depth which confirms DAPI results. These results suggest that the triblock-coated HA/Alg porous scaffolds could provide enhanced cell adhesion and proliferation which may be a promising approach for bone tissue-engineering applications.
\end{abstract}

Index Terms-Alginate, cell adhesion, composite, freeze-drying, human mesenchymal stem cells, hydroxyapatite, porous scaffold, tissue engineering.

\section{INTRODUCTION}

Tissue engineering is the science of design and fabrication of new tissues for functional restoration of impaired organs and replacement of lost parts due to cancer, disease and trauma [1], [2]. The three key ingredients for tissue engineering and tissue regeneration are signals, stem cells and Scaffolds [3]. Scaffolds could provide a solid framework for cell growth and differentiation, allowing cell attachment and migration [4]-[6]. Several requirements must be considered in the design of three-dimensional (3D) scaffolds for tissue engineering [7]-[9]. High porosity is a major factor that is desired to increase the specific surface area for cell attachment and tissue in-growth in scaffolds [10]. The pore size must be large enough to allow accommodation of cells so that interconnected pores may facilitate uniform distribution of cells, diffusion of oxygen and nutrient, and waste exchange by cells deep within the construct [11]-[14].

Polymer/ceramic composites may improve mechanical properties compared with polymers, and better structural integrity and flexibility than brittle ceramics. In fact, the

Manuscript received December 9, 2013; revised February 15, 2014.

Masoumeh Haghbin Nazarpak is with New Technologies Research Center (NTRC), Amirkabir University of Technology, P. O. Box: 1591633311, Tehran, Iran (e-mail: haghbin@aut.ac.ir).

Farzaneh Pourasgari is with Razi Institute of Serum And Vaccination, Tehran, Iran (e-mail: pourasgari@ibb.ut.ac.ir). combination of ceramics and polymers could provide reinforced porous structures with enhanced bioactivity and controlled resorption rates [15], [16].

Several conventional methods have been used to fabricate 3-D scaffolds [17]. In particular, freeze drying is a technique including solvent casting method, in which the solvent removing may be accompanied by freeze drying to a more porous structure to be obtained. In this procedure, cavities is produced in the scaffold due to the space occupied by the solvent after drying, and the smaller pores arising from sublimation of the solvent serves as interconnection between the macropores [18].

Natural and synthetic materials can be used for fabrication of porous scaffolds for bone regeneration. Alginate is a naturally occurring anionic and hydrophilic polysaccharide. It is one of the most abundant biosynthesized materials [19], [20], and is derived primarily from brown seaweed and bacteria. Unfortunately some drawbacks to alginate include mechanical weakness and poor cell adhesion. In order to overcome these limitations, the strength and cell behavior of alginate have been enhanced by mixtures with other materials, such as ceramics [20]. In this way, production of composite scaffolds containing ceramics and synthetic polymers provided a scaffold with desirable properties. In this way, a biodegradable Alg/HA composite scaffolds with different weight ratio for efficient bone tissue engineering were prepared in the present work. On the next step, we compared cell adhesion and proliferation on the triblock copolymer coated scaffolds with uncoated one. The results showed better cell adhesion on the modified samples.

It is demonstrated in the present work that porous $\mathrm{Alg} / \mathrm{HA}$ scaffolds can be successfully prepared by the proposed freeze-drying method. The prepared scaffolds are highly porous, and have interconnected pores about $50 \mu \mathrm{m}$. Study of the cell-scaffold interaction also demonstrated the ability of the scaffold to support hMSC adhesion and proliferation that suggests its potential application in bone tissue engineering.

\section{Materials AND MethodS}

\section{A. Synthesis of Hydroxyapatite Powder}

Orthophosphoric acid, calcium hydroxide and $\mathrm{NH}_{4} \mathrm{OH}$ were obtained from Aldrich Chemical Co. Hydroxyapatite powders were synthesized by a wet chemical method, based on the precipitation of HA particles from aqueous solution. The synthesis procedure involved drop by drop addition of the $\mathrm{H}_{3} \mathrm{PO}_{4}$ solution $(0.3 \mathrm{M})$ into an aqueous suspension of $\mathrm{Ca}(\mathrm{OH})_{2}(0.5 \mathrm{M})$ while stirring vigorously for about $24 \mathrm{~h}$. Simultaneously, ammonia hydroxide solution was added to adjust $\mathrm{pH}$ at 10-11. Then, the obtained white precipitate was aged for 7 days, decanted, rinsed with deionized water, and 
filtered. After filtration, the precipitate was dried in an oven at $70{ }^{\circ} \mathrm{C}$ for $24 \mathrm{~h}$. Finally, it was heated at $1000{ }^{\circ} \mathrm{C}$ for $1 \mathrm{~h}$ in a conventional furnace under air atmosphere.

\section{B. Scaffold Fabrication}

Sodium alginate $\left(29 \mathrm{cP}\right.$ for $1 \%$ at $\left.25^{\circ} \mathrm{C}\right)$ was obtained from Sigma Chemical Co., triblock copolymer were prepared in our laboratory [21], [22]. To prepare the composite scaffolds, different weight ratios hydroxyapatite suspension were prepared using aqua-sonication for $20 \mathrm{~min}$ and added into the prepared alginate solution. Then, the gelation process was started by spraying $1.0 \mathrm{M} \mathrm{CaCl}_{2}$ on the mixture.

Next, the gels were cast in moulds (12 mm diameter) and frozen in freezer overnight. Next, the frozen samples were freeze dried. Some of the samples are used as prepared. For the coated ones, the triblock copolymer synthesized in laboratory according to procedure previously reported [21], [22] dissolved in ethanol was used as coating on some of samples and finally air dried.

\section{RESULTS}

\section{A. X-Ray Diffraction}

$\mathrm{X}$-ray diffraction was performed to determine phase structure of the scaffolds using XRD (INEL, EQuinox 3000, France). The XRD pattern of the sample indicated the presence of hydroxyapatite phase as shown in Fig. 1. In addition, there was no evidence of formation of other unwanted phases, which confirms the purity of the powder is appropriate for biomedical applications. Also the sharpness of the peaks revealed its high crystallinity.

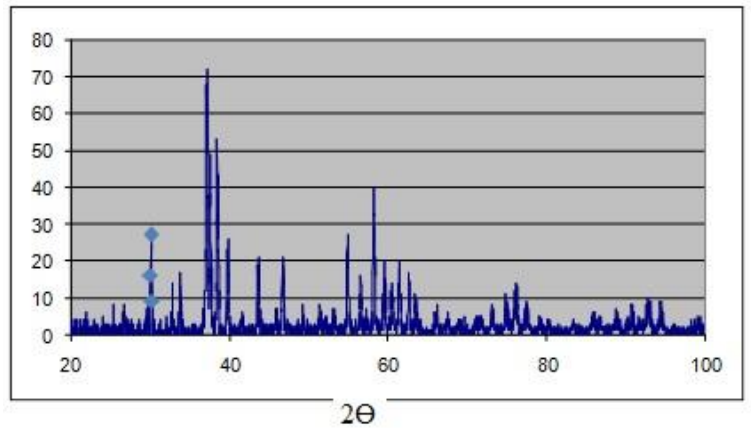

Fig. 1. XRD pattern of hydroxyapatite powder prepared in wet chemical method compared with the reference hydroxyapatite pattern.

\section{B. FTIR Analysis}

FTIR analysis (BRUKER VECTOR 33, Germany) was performed using $\mathrm{KBr}$. The result is shown in Fig. 2. As it is seen the 635 and $3570 \mathrm{~cm}^{-1}$ bands correspond to $\mathrm{OH}^{-}$group, to strongly adsorbed and/or bound $\mathrm{H}_{2} \mathrm{O} . \mathrm{H}_{2} \mathrm{O}$ band was also observed at $1640 \mathrm{~cm}^{-1}$. A strong band of $\mathrm{PO}_{4}{ }^{3-}$ group was also seen at 1046, 962, 602 and $571 \mathrm{~cm}^{-1}$. The bands obtained for respective phosphate and hydroxyl groups of pure HA, were in agreement with other published data.

\section{Particle size Distribution (PSD) Analysis}

The mean diameter and size distribution of hydroxyapatite particles were measured by NANOPHOX particle size analyser (Sympatec GmbH, Germany) which is shown in Fig. 3. As can be seen the average particle size of powder is between $1-5 \mu \mathrm{m}$ and the $50 \%$ of the particles are about 2.5 $\mu \mathrm{m}$.
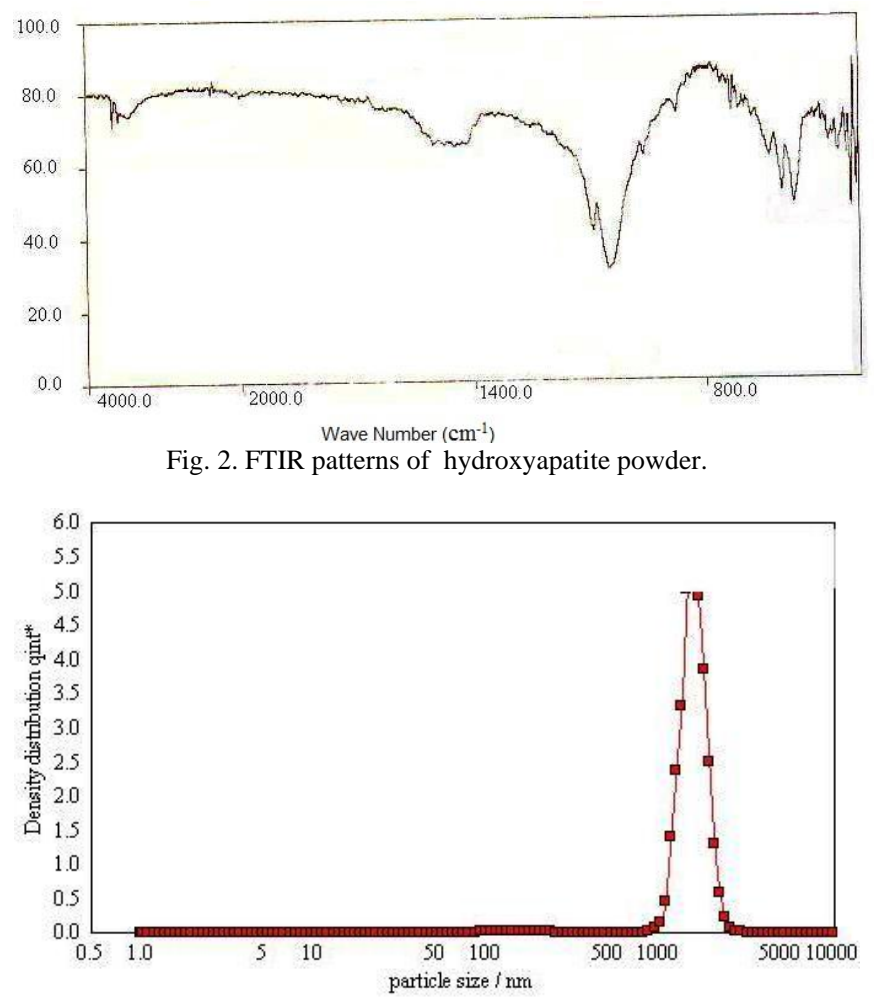

Fig. 3. Particle size distribution of hydroxyapatite particles.

\section{Surface Area of Scaffolds}

The specific surface area was measured by the chromatographic method using Brunauer, Emmett and Teller (B.E.T) model by nitrogen adsorbtion (Bellsorp II, Japan). The result showed that the surface area of the scaffolds were about $57 \mathrm{~m} 2 / \mathrm{g}$ which reveals their relatively high porosity.

\section{E. Microstructure of the Scaffolds}

Microstructure of the scaffolds was studied by scanning electron microscopy (SEM) (XL30 Philips) at an accelerating voltage of $15 \mathrm{kV}$. Before observation, the scaffolds were coated with gold using a sputter coater (BAL-TEC, SCDOOS, Switzerland).

Morphology of the porous scaffolds was characterized using scanning electron microscope (Fig. 4) showed the diameter of pores about 50 micrometer using image analysis software in which a value of $10 \mu \mathrm{m}$ has been suggested as necessary for cellular infiltration.

\section{F. Cell Culture}

Dulbecco Modified Eagle's Medium (DMEM), fetal bovine serum (FBS), phosphate buffered saline (PBS) and trypsin-EDTA were purchased from Gibco, Singapore. The samples were sterilized by UV exposure under a laminar flow hood for $10 \mathrm{~min}$ on each side and placed in DMEM for one day in order to be compatible. Cells used for culturing were human mesenchymal stem cells, originally isolated from bone marrow. The cells were cultivated in DMEM, supplemented with $10 \%$ FBS and $100 \mathrm{U} / \mathrm{ml}$ penicillin-streptomycin-amphotercin, at $37{ }^{\circ} \mathrm{C}$ in $5 \%$ of $\mathrm{CO}_{2}$. Then, scaffolds were placed and immobilized in culture dishes. HMSCs suspended in culture medium (104 cells $/ \mathrm{ml}$ ) were then added in the dishes to allow the in growth of cells 
to the scaffolds. The culture medium was changed every two days. After incubation in various periods, cells attached on the scaffolds were harvested for analysis.

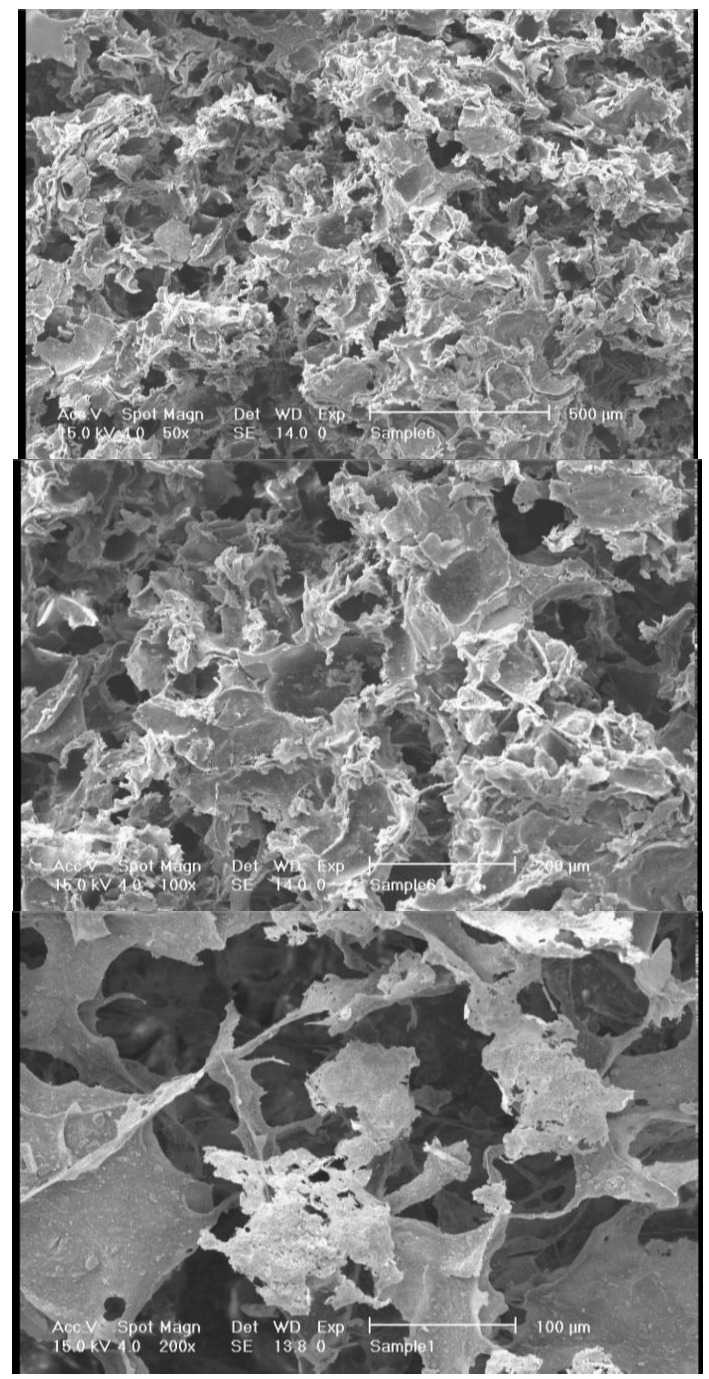

Fig. 4. Microstructure of the porous scaffolds.

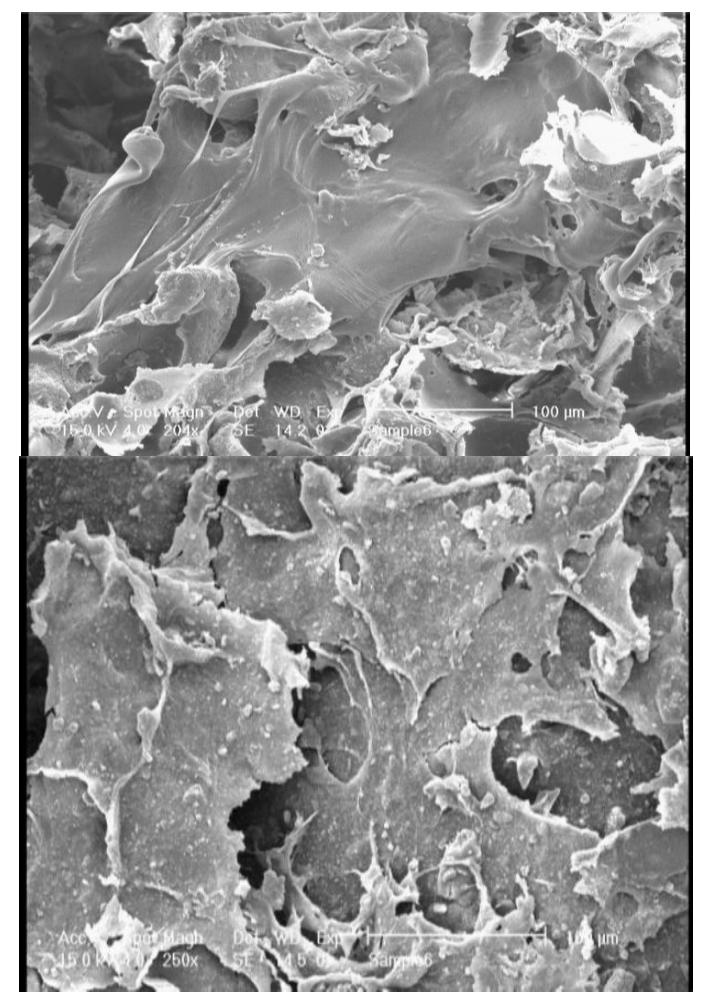

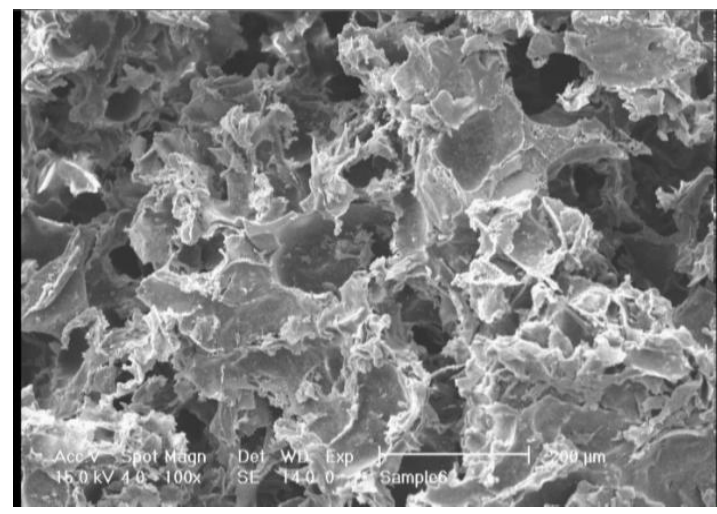

Fig. 5. SEM photographs of cells morphology on the scaffolds

\section{G. Morphology of Cells}

Cell morphology on the scaffold was also investigated by scanning electron microscopy that is shown in Fig. 5. The cell-loaded scaffolds were rinsed with PBS after 3 day of cell seeding and fixed in glutaraldehyde $2.5 \%$ for $1 \mathrm{~h}$. For dehydrating the scaffolds were placed in a series of gradient of alcohol concentration and then dried.

The results indicated that the mesenchymal stem cells cultured in scaffolds can be seen not only in the surface of the scaffold, but also inside the pores. The images showed the perfect adhesion of cells to scaffold surface outside and inside the pores. Adhesion structures resembling tight junctions were present. The cells elongations and their interconnection forming a cell net were observed clearly. Cells that attach themselves to the scaffold, but spread little might show lower proliferative rates than those with greater spreading. These scaffolds allowed flattening and spreading of the cells, showing adequate cell shape for proliferation and secretion functions.

\section{H. DAPI Fluorescent Staining}

The cells on the scaffolds were fixed with $4 \%$ paraformaldehyde. Samples were then washed twice with PBS, incubated with 4, 6-diamidino-2-phenylindole (DAPI;Sigma Chemical Co.) for 30 seconds to label nuclei of the cells and again were rinsed twice with PBS. The immunofluorescence images were obtained by using a fluorescence microscope (Nikon, Eclipse).

DAPI fluorescent staining was carried out after 3 days cultivation which is shown in Fig. 6. In DAPI staining, bright fluorescence revealed the presence of nuclei. As can be seen, the samples with more hydroxyapatite percent and/ or coated with triblock copolymer had better cell adhesion.

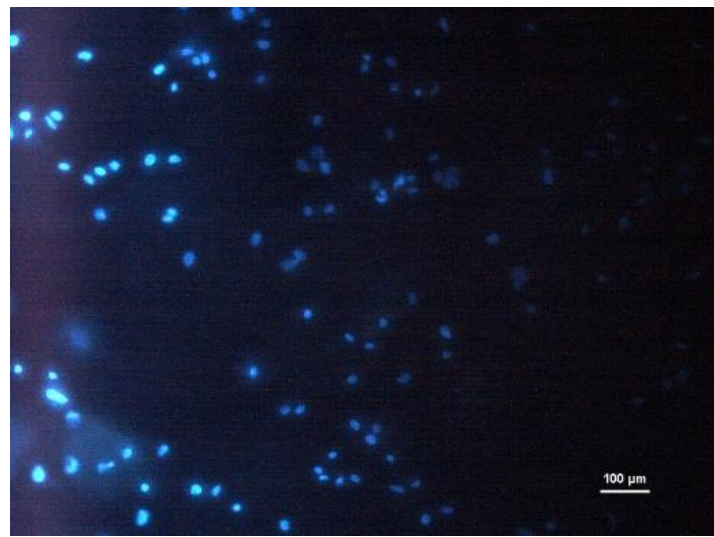




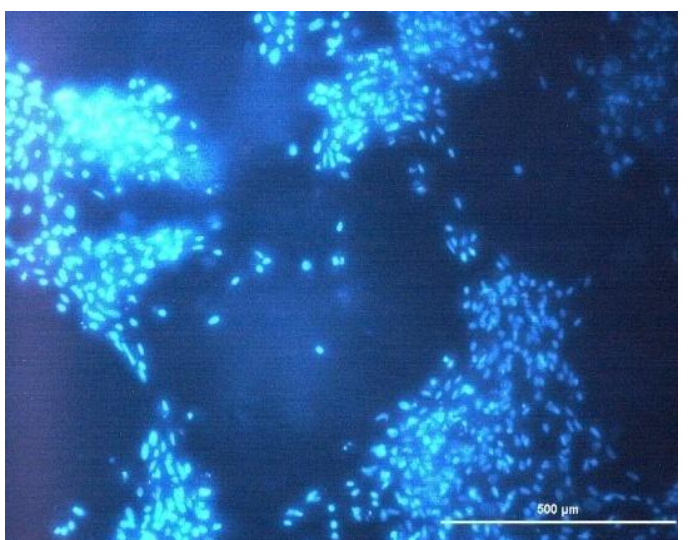

Fig. 6. DAPI staining results of coated samples $3 \%$ hydroxyapatite suspension \& $2 \%$ alginate solution (up) and $6 \%$ hydroxyapatite suspension $\& 2 \%$ alginate solution (down)

\section{CONCLUSION}

In the present work, it is demonstrated that porous $\mathrm{Alg} / \mathrm{HA}$ scaffolds was successfully prepared by the proposed freeze-drying method. The prepared scaffolds were characterized, which the results showed their high porosity, and interconnected pores about $50 \mu \mathrm{m}$. Also, the cell culture results revealed that the matrix was not cytotoxic and the cells were strongly adhered to the substrate in the first hours of cell/ substrate contact. The ability of these scaffolds to support hMSC adhesion and proliferation suggests its potential application in tissue engineering.

It is concluded that these scaffolds are promising materials for tissue engineering, providing a good environment for the adhesion and proliferation of cells. However, in the next step, the tests will be focused on the osteogenic differentiation capability of mesenchymal stem cells seeded on these scaffolds for bone tissue engineering.

\section{REFERENCES}

[1] A. H. Reddi, "Role of morphogenetic proteins in skeletal tissue engineering and regeneration," Nat Biotechnol, vol. 16, pp. 247-52, 1998.

[2] A. H. Reddi, "Symbiosis of biotechnology and biomaterials: applications in tissue engineering of bone and cartilage," $J$ Cell Biochem, vol. 56, pp. 192-195, 1994.

[3] A. H. Reddi and C. Huggins, "Biochemical sequences in the transformation of normal fibroblasts in adolescent rats," in Proc. Natl Acad Sci, vol. 69, pp. 1601-1605, USA 1972.

[4] G. Chen, T. Ushida, and T. Tateishi, "Development of biodegradable porous scaffolds for tissue engineering," Materials Science Engineering, vol. C17, C17, pp. 63-69, 2001.

[5] D. W. Hutmacher and A. J. Garcia, "Scaffold-based bone engineering by using genetically modified cells," Gene, vol. 347, pp. 1-10, 2005.

[6] X. Zhu, W. Cui, X. Li, and Y. Jin, "Electrospun fibrous mats with high porosity as potential scaffolds for skin tissue engineering," Biomacromolecules, vol. 9, pp. 1795-1801, 2008.

[7] L. Budyanto, C. P. Ooi, and Y. Q. Goh, "Fabrication and characterization of porous poly (L-lactide) PLLA scaffolds using liquid-liquid phase separation," IFMBE Proc., vol. 21, pp. 322-325, 2008.

[8] P. A. Gunatillake and R. Adhikari, "Biodegradable synthetic polymers for tissue engineering," Eur Cells Materials, vol. 5, pp. 1-16, 2003.

[9] S. Yang, K. F. Leong, Z. Du, and C. K. Chua, "The design of scaffolds for use in tissue engineering: Part I. Traditional factors," Tissue Engineering, vol. 7, pp. 679-689, 2001.

[10] S. Gong, J. Dong, S. T. Xue, and J. Y. Wang, "A novel porous natural polymer scaffold for tissue engineering," in Proc. 2005 IEEE Engineering Medicine Biology 27th Annual Conf, pp. 4884-4887, Shanghai, Sept. 2005.
[11] R. A. Horch, N. Shahid, A. S. Mistry, and M. D. Timmer, "Nanoreinforcement of poly (propylene fumarate)-based networks with surface modified alumoxane nanoparticles for bone tissue engineering," Biomacromolecules, vol. 5, pp. 1990-1998, 2004.

[12] C. T. Buckley and K. U. O'Kelly, "Regular scaffold fabrication techniques for investigations in tissue engineering," Topics Bio-Mechanical Engineering, pp. 147-166, 2004.

[13] F. Lyons, S. Partap, and F. J. O'Brien, "Part 1: Scaffolds and surfaces," Technology Health Care, vol. 16, pp. 305-317, 2008.

[14] L. M. Mathieu, P. E. Bourban, and J. E. Ma ${ }^{\circ}$ nson, "Processing of homogeneous ceramic/polymer blends for bioresorbable composites," Composites SciTechnol, vol. 66, pp. 1606-1614, 2006.

[15] M. Neumann and M. Epple, "Composites of calcium phosphate and polymers as bone substitution materials," Eur Jtrauma, vol. 32, pp. 125-131, 2006.

[16] T. Tyson, A. F. Wistrand, and A. C. Albertsson, "Degradable porous scaffolds from various L-lactide and trimethylene carbonate copolymers obtained by a simple and effective method," Biomacromolecules, vol. 10, pp. 149-154, 2009.

[17] J. H. de Groot, H. W. Kuijper, and A. J. Pennings, "A novel method for fabrication of biodegradable scaffolds with high compression moduli," J Materials Science: Mater Med., vol. 8, pp. 707-712, 1997.

[18] R. P. Narayanan, G. Melman, N. J. Letourneau, N. L. Mendelson, and A. Melman, "Photodegradable iron(III) cross-linked alginate gels," Biomacromolecules, vol. 13, pp. 2465-2471, 2012.

[19] G. Skjak-Braerk, H. Grasdalen, and O. Smidsrod, "Inhomogeneous polysaccharide ionic gels," Carbohydr. Polym, vol. 10, pp. 31-54, 1989.

[20] J. Cuy. (2004). Biomaterials Tutorial: Natural Polymers. University of Washington Engineered Biomaterials. [Online]. Available: http://www. uweb.engr.washington.edu/.

[21] F. Najafi and M. N. Sarbolouki, "Synthesis and Characterization of Block Copolymers from Aromatic Diols, Fumaric Acid," Sebacic Acid and PEG, J Appl Polym Sci, 2003, vol. 90, pp. 2358-2363.

[22] F. Najafi and M. N. Sarbolouki, "Biodegradable micelles/polymersomes from fumaric/sebacic acids and poly(ethylene glycol)," Biomaterials, vol. 24, pp. 1175-1182, 2003.

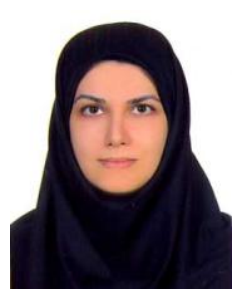

Masoumeh Haghbin Nazarpak was born in Iran and obtained her Ph.D from Amirkabir University of Technology of Iran in Biomedical Engineering (Biomaterials). She is now the academic staff of New Technologies Research Center of Amirkabir University of Technology and works in the fields of biomaterials, tissue engineering and drug delivery systems.

She has published a few papers such as Nanocrystalline fluorine-substituted hydroxyapatite $\left[\mathrm{Ca}_{5}\left(\mathrm{PO}_{4}\right)_{3}(\mathrm{OH})_{1-\mathrm{x}} \mathrm{F}_{\mathrm{x}}\right.$ $(0 \leq \mathrm{x} \leq 1)$ ] for biomedical applications: Preparation and characterization, Micro \& Nano Letters, 7, Issue 2 ( 2012), Injectable and bioresorbable calcium phosphate delivery system with gentamicin sulphate for treatment of bone diseases: in vitro study, Advances in Applied Ceramics, Volume 110, Number 8 (2011), Preparation of a novel porous scaffold from poly (lacticco-glycolic acid)/hydroxyapatite, Asian Biomedicine, Vol. 5 No. 4 (2011).

Dr. Masoumeh Haghbin Nazarpak is the member of professional societies such as Iranian Ceramic Society (ICERS), Iranian Society of Biomedical Engineering (ISBE), The Australian Research Network for Advanced Materials (ARNAM), Biomaterials Research Centre, Göteborg.

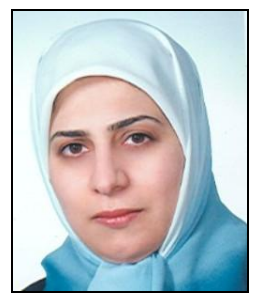

Farzaneh Pourasgari was born in Iran and obtained her Ph.D in Biochemistry from University of Tehran, Institute of Biochemistry and Biophysics. She is now the academic staff of Razi Vaccine and Serum Research Institute and one her fields of works is stem cell culture and differentiation.

She has published a few papers such as "Preparation of a novel porous scaffold from poly (lacticco-glycolic acid)/ hydroxyapatite, Asian Biomedicine, Vol. 5 No. 4 ( 2011)" and "Low cytotoxicity capacity of Dendrosomes as a carrier for intranasally administered DNA vaccines. Molecular Biology Reports 2007, 36(1):105-9”.

Dr. Farzaneh Pourasgari is the member of professional societies such as Biochemistry Society, Iranian Genetic Society and Iranian Stem Cell Society. 